\title{
Waste to Energy - Energy Recovery of Green Bin Waste: Incineration/Biogas Comparison
}

\author{
Lasse Tobiasen • Kristian Kahle • Claus Hindsgaul • \\ Bettina Kamuk
}

Published online: 15 October 2014

(C) Springer International Publishing AG 2014

\begin{abstract}
This study presents how to determine marginal incinerator energy efficiencies. This concept should be applied in assessments of the treatment of specific waste streams to create a level playing field when comparing different technologies, for instance in life-cycle assessments. The marginal efficiencies depend on the technical level, the surrounding energy system, and the waste type/heating value. The concept of marginal efficiency is in this article applied to the treatment of green bin waste. The thermal treatment options considered are incineration and anaerobic digestion with biogas combustion in a reciprocating gas engine. The comparison is made only with regard to energy yield. The comparison is carried out for three different types of energy systems: power producing, combined heat and power, and combined heat and power with flue gas condensation. For a power-only energy system, the electrical efficiency of anaerobic digestion is found to be comparable to incineration. However, for an energy system with district heating as an option, the energy recovery of incineration is much higher than biogas. Furthermore, if the waste heat recovery technology flue gas condensation is used, the total efficiency of incineration is almost twice as high as the biogas technology, with the same boundary conditions applied. Although this study produces specific figures of energy recovery yields for a number of different scenarios for incineration and biogas production, the aim of the study is not a technology comparison as such. A proper technology comparison, including life-cycle assessments, should deal with many other issues than just energy recovery, for instance, other environmental factors, initial cost, operating and maintenance costs, and commercial aspects. However, this study does show that when
\end{abstract}

L. Tobiasen $(\bowtie) \cdot$ K. Kahle $\cdot$ C. Hindsgaul $\cdot$ B. Kamuk

Ramboll Energy - Waste-to-Energy, Hannemanns Allé 53, DK

2300 København S, Denmark

e-mail: 1st@ramboll.com

URL: http://www.ramboll.com/energy undertaking such technology assessments, it is crucial to the results that: - Proper and relevant boundary conditions are applied: if district heating is possible, this changes results dramatically. Optimally, a specific site should form the basis for a comparison. $\bullet$ Energy recovery efficiencies must be linked to the actual waste steam considered. For green bin waste, this study has shown that margin efficiencies of up to $125 \%$ can be achieved. This is much higher than efficiencies reported in the literature $(95 \%)[1 \bullet, 2 \bullet]$. Therefore, one main conclusion is that efficiencies used for comparisons of technology must be wastetype (and calorific-value) specific to obtain reliable results in the comparisons.

Keywords Incineration $\cdot$ Biogas $\cdot$ Energy recovery $\cdot$ Waste streams $\cdot$ Green bin waste $\cdot$ Biomass

\section{Introduction}

This review compares the energy recovery of green bin waste (GBW) from anaerobic digestion and mass burn incineration, using a marginal contribution approach. The review does not compare the environmental performance of the two types of technologies, and does not compare cost.

GBW in this paper is defined as the organic fraction of municipal solid waste (MSW) separated perfectly in a separate waste stream. This waste stream can be separated by either source separation or central sorting (see Fig. 1).

Anaerobic digestion vs. incineration of GBW has in multiple studies been assessed using life-cycle assessment methodology, i.e., $[1 \cdot 3-5]$,. The final conclusion in most publications is highly related to the boundary conditions assumed, such as the energy system in which the study applies to, that being the fuel of the substituted energy, degree of energy recovery, and whether or not waste heat is used (e.g., district heating or industrial process heating). The substituted energy is a highly 


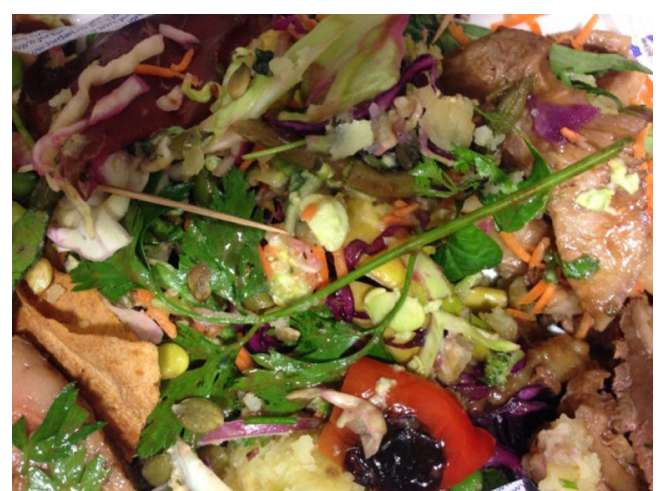

Fig. 1 Green bin waste consisting of discarded vegetables, fruit, and other food waste [source: picture from Ramboll's main office, canteen green waste bin]

influential factor, especially with regard to impacts related to global warming and resource consumption. However, studies tend to evaluate large and fundamentally different scenarios, making it difficult to compare specific treatment technologies.

Furthermore, the assumed energy efficiencies of the treatment technologies to be compared are crucial for the results and conclusions. The energy efficiency of a treatment technology is most commonly assumed independent of waste composition $[1 \bullet 2 \bullet]$, and in some cases not explicitly mentioned. However, in reality, the energy efficiency of incineration varies among waste types depending on chemical composition and especially moisture content, let alone the actual process configuration of the incineration system.

The scope of this review is to suggest how to determine the energy efficiency of a specific waste type using a marginal approach, i.e., the contribution of adding one additional ton of a specific waste type. The overall energy efficiency of incineration is equal to the linear combination of all the waste types and their corresponding marginal efficiencies.

The methodology in this paper is applied to the incineration of GBW, as this waste type in particular can have very different efficiencies compared with average considerations. This realization is of very high importance in the case where the incineration plant is equipped with flue gas condensation for additional heat recovery. This fact has yet to be described in the literature and has not been included in previous assessments. Determining the energy efficiency of specific waste streams is not a trivial task, and requires the use of thorough thermodynamic modeling. The thermodynamic modeling has been undertaken by the authors themselves using the commercial engineering software tool Thermoflex from Thermoflow [www.thermoflow.com].

The technological treatment steps compared in this study are anaerobic digestion of GBW and mass burn incineration. Incineration of GBW will occur in co-combustion with mixed MSW (see Fig. 2).

The results of the determined marginal efficiencies for the incineration of GBW will be compared with the energy yield following the use of biogas from anaerobic digestion. The comparison is performed for different scenarios to underline the importance of the defined boundary conditions and the choice of energy recovery technology.

Environmental impacts of treatment technologies other than degree of energy recovery are not included in this study. Furthermore, energy consumption from the pre-treatment of organic waste and parasitic consumption in the anaerobic digestion treatment option has not been included.
Fig. 2 Treatment technology systems. $M S W$ municipal solid waste

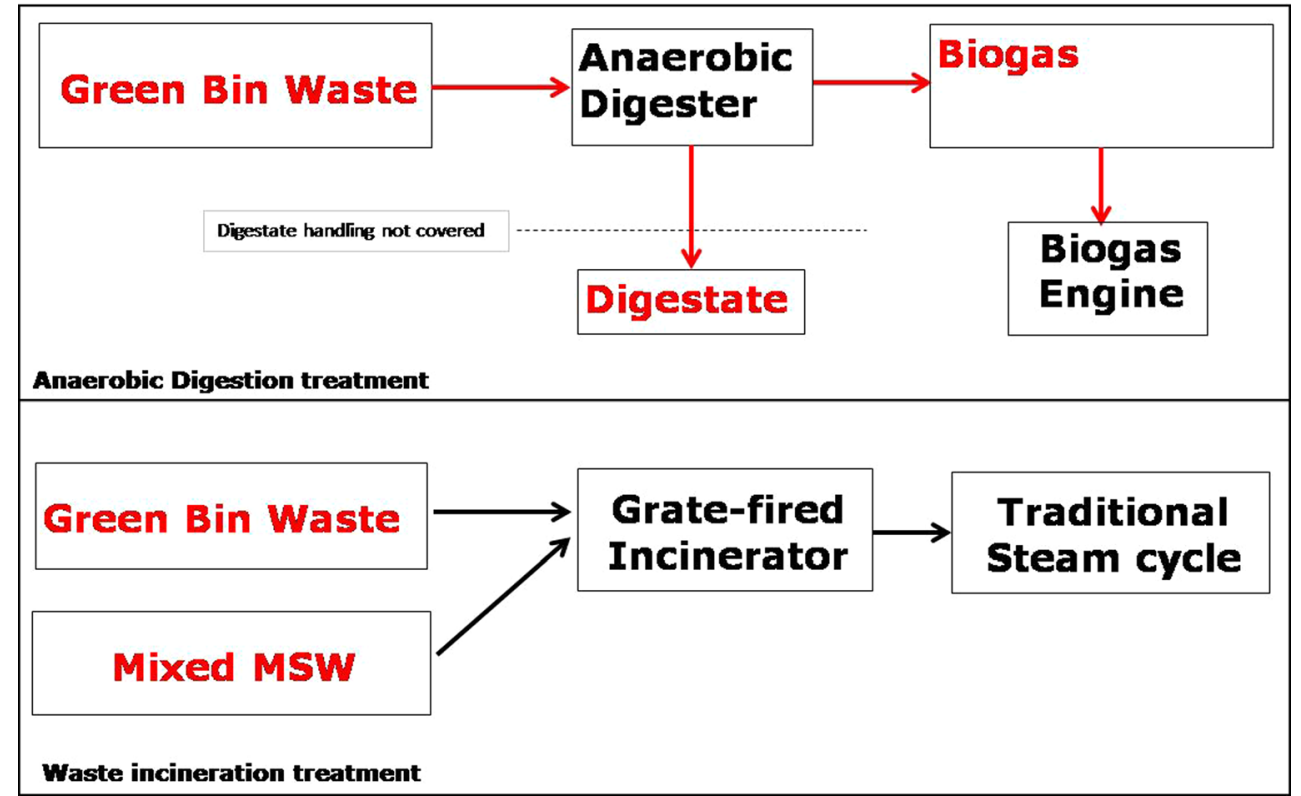


Table 1 Chemical composition and calculated heating values for green bin waste. Sample No. refers to the sample numbering used in the original (6)

\begin{tabular}{|c|c|c|c|c|c|c|c|c|c|c|c|c|c|c|c|c|}
\hline Sample No. & 1 & 2 & 3 & 4 & 5 & 6 & 7 & 8 & 9 & 10 & 11 & 12 & 13 & 14 & 17 & Average \\
\hline Moisture $[\% \mathrm{w} / \mathrm{w}]$ & 69 & 74 & 72 & 70 & 66 & 69 & 67 & 70 & 71 & 83 & 75 & 78 & 63 & 72 & 68 & 71.1 \\
\hline Total solids $[\% \mathrm{w} / \mathrm{w}]$ & 31 & 26 & 28 & 30 & 34 & 31 & 33 & 30 & 29 & 17 & 25 & 22 & 37 & 28 & 32 & 28.9 \\
\hline Volatile solids [\% total solids] & 87 & 91 & 87 & 80 & 87 & 84 & 82 & 81 & 92 & 85 & 87 & 87 & 85 & 92 & 87 & 86.3 \\
\hline \multicolumn{17}{|l|}{ Elements } \\
\hline $\mathrm{K}[\%$ total solids $]$ & 1 & 1.1 & 1 & 0.9 & 1 & 1 & 0.9 & 1 & 1.1 & 1.3 & 0.9 & 1.1 & 0.8 & 1 & 1 & 1.0 \\
\hline $\mathrm{P}[\%$ total solids $]$ & 0.5 & 0.4 & 0.6 & 0.5 & 0.5 & 0.5 & 0.5 & 0.6 & 0.3 & 0.4 & 0.3 & 0.3 & - & 0.4 & 0.3 & 0.4 \\
\hline $\mathrm{N}[\%$ total solids $]$ & 2.8 & 2.6 & 2.5 & 2.3 & 2.6 & 2.2 & 2.4 & 2.7 & 2.9 & 2.8 & 2.9 & 2.6 & 2.7 & 2.5 & 3.1 & 2.6 \\
\hline $\mathrm{C}[\%$ total solids $]$ & 48 & 49 & 49 & 46 & 48 & 45 & 46 & 50 & 50 & 47 & 52 & 48 & 49 & 50 & 48 & 48.3 \\
\hline $\mathrm{H}[\%$ total solids $]$ & 7.2 & 7.2 & 7.1 & 6.7 & 7.2 & 6.4 & 6.9 & 7.2 & 7.6 & 7.1 & 7.8 & 7 & 7.4 & 7.3 & 7 & 7.1 \\
\hline $\mathrm{S}[\%$ total solids] & 0.2 & 0.2 & 0.2 & 0.2 & 0.2 & 0.2 & 0.2 & 0.2 & 0.2 & 0.2 & 0.2 & 0.2 & 0.2 & 0.2 & 0.2 & 0.2 \\
\hline Lower heating value $[\mathrm{MJ} / \mathrm{kg}]=[\mathrm{GJ} / \mathrm{ton}]$ & 4.7 & 3.6 & 4.1 & 4.3 & 5.4 & 4.1 & 4.9 & 5.0 & 4.5 & 1.4 & 3.9 & 2.6 & 6.4 & 4.1 & 4.9 & 4.3 \\
\hline Higher heating value $[\mathrm{MJ} / \mathrm{kg}]=[\mathrm{GJ} /$ ton $]$ & 6.9 & 5.8 & 6.3 & 6.4 & 7.5 & 6.2 & 7.1 & 7.1 & 6.7 & 3.7 & 6.2 & 4.8 & 8.6 & 6.3 & 7.0 & 6.4 \\
\hline
\end{tabular}

\section{Method}

The following sections describe the fuels used in the assessment, the treatment technology with different boundary conditions (scenarios), the main modeling assumptions, and finally, a description of how to determine the marginal incinerator efficiency.

\section{Fuel Definitions}

\section{Green Bin Waste}

The fuel definition of GBW used in this paper is based on characterization samples of actual collected GBW from single family and apartment housing in Denmark [6•]. The lower and higher heating values of the GBW have been calculated using Schwanecke's formula [7] The composition of GBW samples and calculated heating values are presented in Table 1. Unless otherwise stated, heating values and efficiencies will be based on a lower heating value in the present article.

The volatile solids (VS) of the GBW represent the combustible fraction of the waste. The remaining solids in the waste are inorganic and remain on solid form as ash, after complete combustion.

Table 2 Component/element composition of mixed green bin waste (lower heating value $=$ $4.3 \mathrm{GJ} /$ ton). Weight percentage is based on wet weight

\begin{tabular}{ll}
\hline Component/element & Weight \% \\
\hline Moisture & 71.1 \\
Ash & 4.0 \\
Carbon & 13.9 \\
Hydrogen & 2.1 \\
Nitrogen & 0.76 \\
Chlorine & 0.0 \\
Sulfur & 0.06 \\
Oxygen & 8.1 \\
\hline
\end{tabular}

The average elemental composition and calculated heating values as presented in Table 1 are used in the thermodynamic modeling, see also Table 2.

\section{Mixed Municipal Solid Waste}

Modeling the treatment of GBW using mass burn incineration is performed as co-combustion with mixed MSW. The fuel definition for mixed MSW used in this paper is presented in Table 3.

The presented composition of mixed MSW results in a lower heating value of $11.5 \mathrm{GJ} / \mathrm{ton}$. The fuel composition has an influence on combustion products, which affects the possible energy yield in thermodynamic modeling. However, as the results of the modeling will be the marginal efficiency, the selected composition of MSW is not crucial to the results.

Mass Burn Incineration

\section{Waste Incineration with Power Production}

Modern, mass burn incineration facilities serve the purpose of reducing mass/volume of the waste, destroying pollutants, and

Table 3 Component/element composition of mixed municipal solid waste (lower heating value $=11.5 \mathrm{GJ} /$ ton $)$

\begin{tabular}{ll}
\hline Component/element & Weight \% \\
\hline Moisture & 22.3 \\
Ash & 19.0 \\
Carbon & 30.1 \\
Hydrogen & 4.2 \\
Nitrogen & 0.7 \\
Chlorine & 0.6 \\
Sulfur & 0.2 \\
Oxygen & 22.9 \\
\hline
\end{tabular}




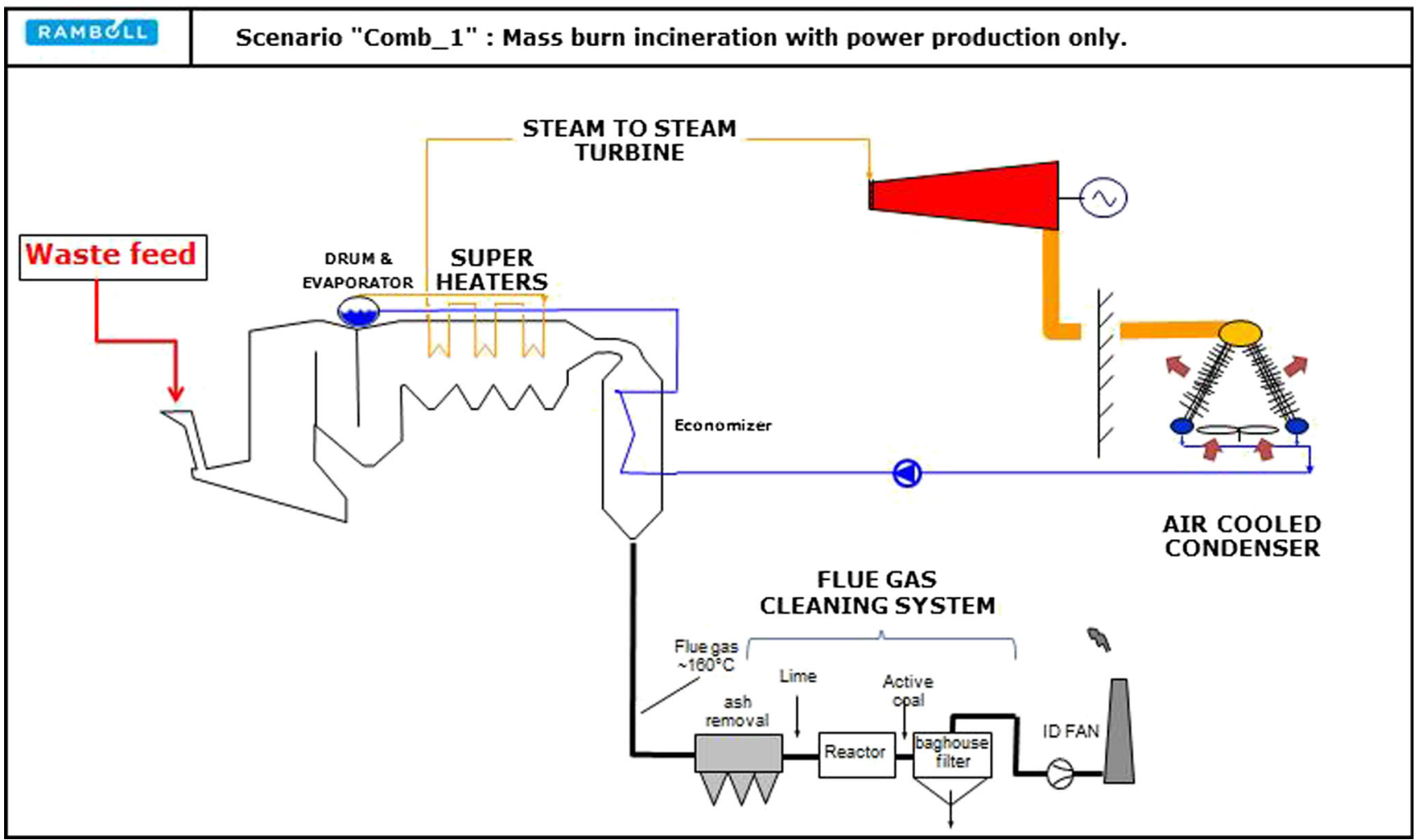

Fig. 3 The "Comb_1" scenario using mass burn incineration in a power-only producing unit

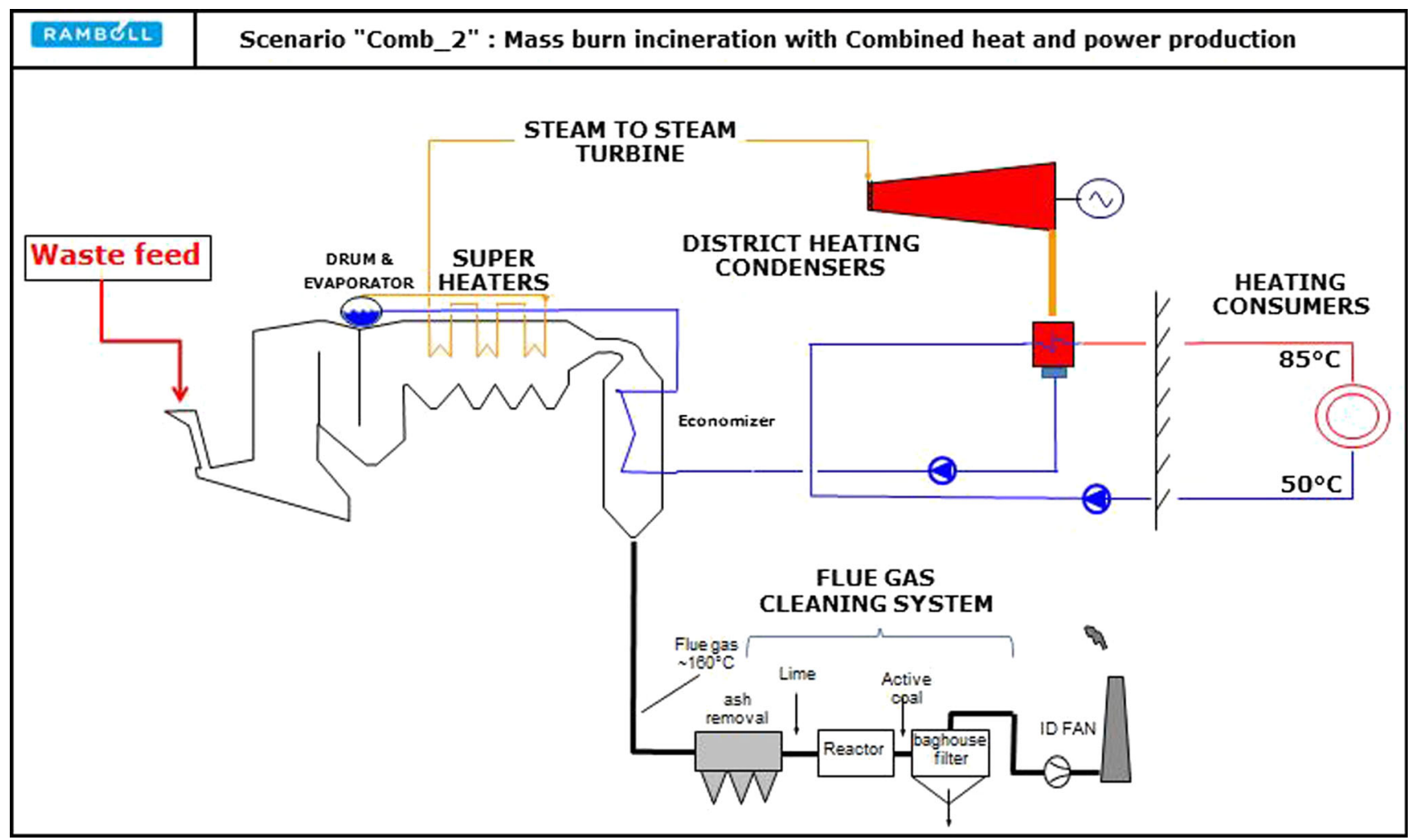

Fig. 4 The "Comb_2" scenario using mass burn incineration in a combined heat and power producing unit 
Table 4 Simple composition, operation, and resulting flue gas water concentration and flue gas dew point of common fuels in optimized combustion systems. Note that very large variations are possible for
MSW. The MSW in this table corresponds to the MSW used in the article. $M S W$ municipal solid waste

\begin{tabular}{lllllllll}
\hline Example fuels & $\begin{array}{l}\mathrm{C} \\
\text { \%wt. }\end{array}$ & $\begin{array}{l}\mathrm{H} \\
\text { \%wt. }\end{array}$ & $\begin{array}{l}\mathrm{O} \\
\text { \%wt. }\end{array}$ & $\begin{array}{l}\text { Ash } \\
\text { \%wt. }\end{array}$ & $\begin{array}{l}\mathrm{H}_{2} \mathrm{O} \\
\text { \%wt. }\end{array}$ & $\begin{array}{l}\mathrm{O}_{2} \text { in flue gas } \\
\text { \%vol (wet) }\end{array}$ & $\begin{array}{l}\mathrm{H}_{2} \mathrm{O} \text { in flue gas } \\
\text { \%vol }\end{array}$ & $\begin{array}{l}\text { Approximate flue gas dew point } \\
{ }^{\circ} \mathrm{C}\end{array}$ \\
\hline Coal & 66.3 & 4.2 & 7.7 & 14 & 7 & 4 & 7 & $\mathbf{3 9}$ \\
Natural gas & 74.6 & 23.3 & 1.4 & 0 & 0 & 0.9 & 18 & $\mathbf{5 7 . 9}$ \\
MSW (example) & 30.1 & 4.2 & 22.9 & 19 & 22 & 6.8 & 15.2 & $\mathbf{5 4 . 3}$ \\
Straw & 40.5 & 4.9 & 35.9 & 3.8 & 14 & 4.2 & 13.5 & $\mathbf{5 1 . 8}$ \\
Wood chips & 24.7 & 2.9 & 21.1 & 1 & 50 & 4.6 & 12 & $\mathbf{6 3 . 4}$ \\
Wood pellets & 46 & 5.5 & 39 & 1.3 & 8 & 4.3 & $\mathbf{4 9 . 5}$ \\
\hline
\end{tabular}

using the energy content. In mass burn incineration, the waste moves slowly on a moving grate as the waste is combusted. Simply speaking, waste incineration consists of a furnace where the waste is combusted, a boiler where heat from the flue gas is recovered by a closed steam cycle, and a flue gas cleaning system where pollutants in the flue gas are removed prior to release into the atmosphere. For a detailed description of incineration technology, readers are referred to $[8,9]$.

Energy recovery in waste incineration is performed by means of a Rankine steam cycle as known from traditional power plants. Large and modern power-only waste incinerators have a complex set-up, allowing net electric efficiencies of up to approximately $28 \%$ (in special cases, slightly higher). The part of the recovered energy which, primarily due to the fundamental laws of thermodynamics, cannot be converted to electricity is discarded to the surroundings. A modern poweronly plant is used in the comparison in this paper. The scenario with combustion and power-only production in this article is referred to as "Comb_1" and is depicted in Fig. 3.

The power-only-type plant is modeled with an air-cooled condenser technology and a turbine backpressure of 100 mbar.

Combustion of moist fuels, such as GBW, lowers the degree of energy recovery compared with the combustion of mixed MSW. This is owing to evaporated water being emitted at high temperatures. Thus, moist fuels have a higher degree of heat loss.

To what degree the incinerator efficiency is affected is shown in Results.

\section{Waste Incineration with Combined Heat and Power Production}

To increase the degree of energy recovery, it is possible to design a plant as a combined heat and power (CHP)- producing plant. The plant equipment is generally equal to that used for power-only producing units. However, in CHP plants, the energy that cannot be converted to electricity is used. This necessitates a consumer for the heat, such as a district heating network. Most thermal power plants in Scandinavia are connected to a district heating grid. General information on grate-fired waste-toenergy technology in relation to district heating is discussed in [10].

The efficiency for modern CHP incinerators is roughly $25 \%$ electrical efficiency and a heat production of $60 \%$, giving a total plant energy efficiency of $85 \%$. This applies for the average waste composition.

The scenario with mass burn incineration and CHP production is referred to in this article as "Comb_2" and depicted in Fig. 4.

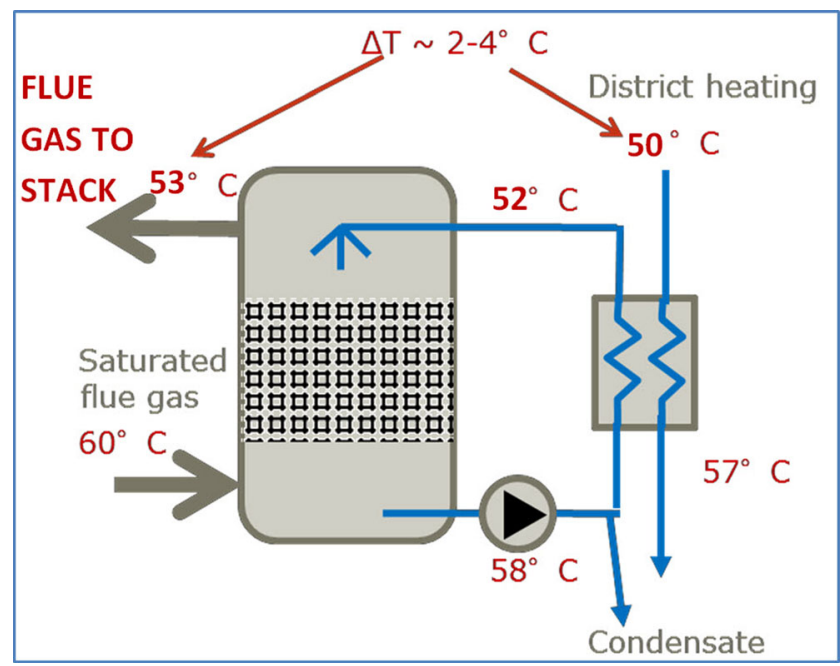

Fig. 5 General principle for flue gas condensation. Water-saturated flue gas enters the flue gas condensation unit, where district heating return water causes the water to condense. The heat released from condensation is recovered by heat exchange with district heating water 
Table 5 Theoretical and measured methane production from 15 pilot-scale tests. The test reactor had a retention time of 15 days. The consequent biogas yield and $\mathrm{CH}_{4}$ content in biogas are also presented (6). The samples correspond to the waste characteristics presented in Table 1

\begin{tabular}{|c|c|c|c|c|c|c|c|c|c|c|c|c|c|c|c|c|}
\hline Sample No. & 1 & 2 & 3 & 4 & 5 & 6 & 7 & 8 & 9 & 10 & 11 & 12 & 13 & 14 & 17 & Average \\
\hline Theoretic $\mathrm{CH}_{4}$ yield $\left[\mathrm{Nm}^{3} \mathrm{CH}_{4} /\right.$ ton VS] & 623 & 594 & 635 & 658 & 612 & 583 & 629 & 734 & 611 & 627 & 697 & 605 & 658 & 591 & 620 & 631.8 \\
\hline Measured $\mathrm{CH}_{4}$ yield $\left[\mathrm{Nm}^{3} \mathrm{CH}_{4} /\right.$ ton VS] & 347 & 340 & 349 & 311 & 353 & 328 & 353 & 322 & 275 & 367 & 410 & 400 & 319 & 289 & 284 & 336.5 \\
\hline Yield [vol \%] & 56 & 57 & 55 & 47 & 58 & 56 & 56 & 44 & 45 & 59 & 59 & 66 & 48 & 49 & 46 & 53.4 \\
\hline Average $\mathrm{CH}_{4}$ content in gas [vol \%] & 61 & 60 & 64 & 60 & 62 & 61 & 62 & 58 & 66 & 64 & 60 & 64 & 62 & 63 & 59 & 61.7 \\
\hline
\end{tabular}

As mentioned for power-only producing units, the degree of energy recovery in CHP units is slightly decreased when combusting moist fuels such as GBW.

\section{Waste Incineration with Combined Heat and Power Production and Flue Gas Condensation}

Flue gas condensation is a technology that allows for near full energy recovery with reference to a higher heating value and is rapidly advancing in the Scandinavian countries. A brief description of the technology is given below.

In flue gas condensation, the cleaned flue gas is cooled below its dew point, at $50-60{ }^{\circ} \mathrm{C}$. When the flue gas temperature is below the dew point, water vapor will condense to liquid form, thus releasing energy as low-temperature heat.

The most important factors for how much energy can be recovered in flue gas condensation are as follows:

- The moisture content of the fuel (adds to the $\mathrm{H}_{2} \mathrm{O}$ content of the flue gas).

- The hydrogen content in the fuel (transformed to $\mathrm{H}_{2} \mathrm{O}$ during combustion).

- If a cooling medium is available to cool the flue gas below its dew point (for instance, district heating return water).

Table 4 shows some examples of common fuels, as well as examples of the concentration of $\mathrm{H}_{2} \mathrm{O}$ in the flue gases under typical combustion conditions in large boilers.

The $\mathrm{O}_{2}$ concentration in flue gas reflects the degree of excess air used in the combustion process. The excess air is controlled to meet certain operation criteria related to combustion and steam production. The amount of excess air in the flue gas affects the $\mathrm{H}_{2} \mathrm{O}$ vapor concentration and thus the dew point of the flue gas. The higher the dew point of the flue gas, the higher the potential for energy recovery using flue gas condensation. Operation of the plant thus influences the potential for energy recovery from flue gas condensation.

Cooling of the flue gas for heat recovery is most commonly done by first quenching the flue gas with water until the saturation point (100\% relative humidity). Second, the saturated flue gas enters a flue gas scrubber, where circulating scrubber fluid is cooled against colder, district heating return water. Heat recovered from flue gas condensation is thus transferred as low-temperature heat to the district heating return water, before the district heating water is heated to its forward temperature by other means (often a steam turbine condenser). The general principle for flue gas condensation is depicted in Fig. 5.

If the district heating network is capable of consuming the excess heat from flue gas condensation, but not able to reach the low, district heating return temperature, the heat can be recovered through a heat pump. Flue gas condensation has yet to be thoroughly technically described in the literature. For more information, readers are referred to suppliers, such as $[11,12]$.

Anaerobic Digestion

\section{Biogas Production}

Organic substances naturally decompose into simpler forms of matter once living has ceased. Decomposition in the absence of oxygen is referred to as anaerobic digestion. The desirable output of the decomposition is

Table 6 Total biogas yield, methane yield, and energy content per ton of anaerobically digested GBW. The presented results are based on figures shown in Tables 1 and 5. GBW green bin waste

\begin{tabular}{lllllllllllllllll}
\hline Sample No. & 1 & 2 & 3 & 4 & 5 & 6 & 7 & 8 & 9 & 10 & 11 & 12 & 13 & 14 & 17 & Average \\
\hline Biogas per ton GBW [Nm 3 /ton GBW] & 153 & 134 & 133 & 124 & 168 & 140 & 154 & 135 & 111 & 83 & 149 & 120 & 162 & 118 & 134 & $\mathbf{1 3 4 . 6}$ \\
$\mathrm{CH}_{4}$ per ton GBW [Nm ${ }^{3} \mathrm{CH}_{4} /$ ton GBW] & 94 & 80 & 85 & 75 & 104 & 85 & 96 & 78 & 73 & 53 & 89 & 77 & 100 & 74 & 79 & $\mathbf{8 2 . 9}$ \\
Energy yield per ton GBW [GJ/ton GBW] & 3.4 & 2.9 & 3.1 & 2.7 & 3.7 & 3.1 & 3.4 & 2.8 & 2.6 & 1.9 & 3.2 & 2.7 & 3.6 & 2.7 & 2.8 & $\mathbf{3 . 0}$ \\
\hline
\end{tabular}




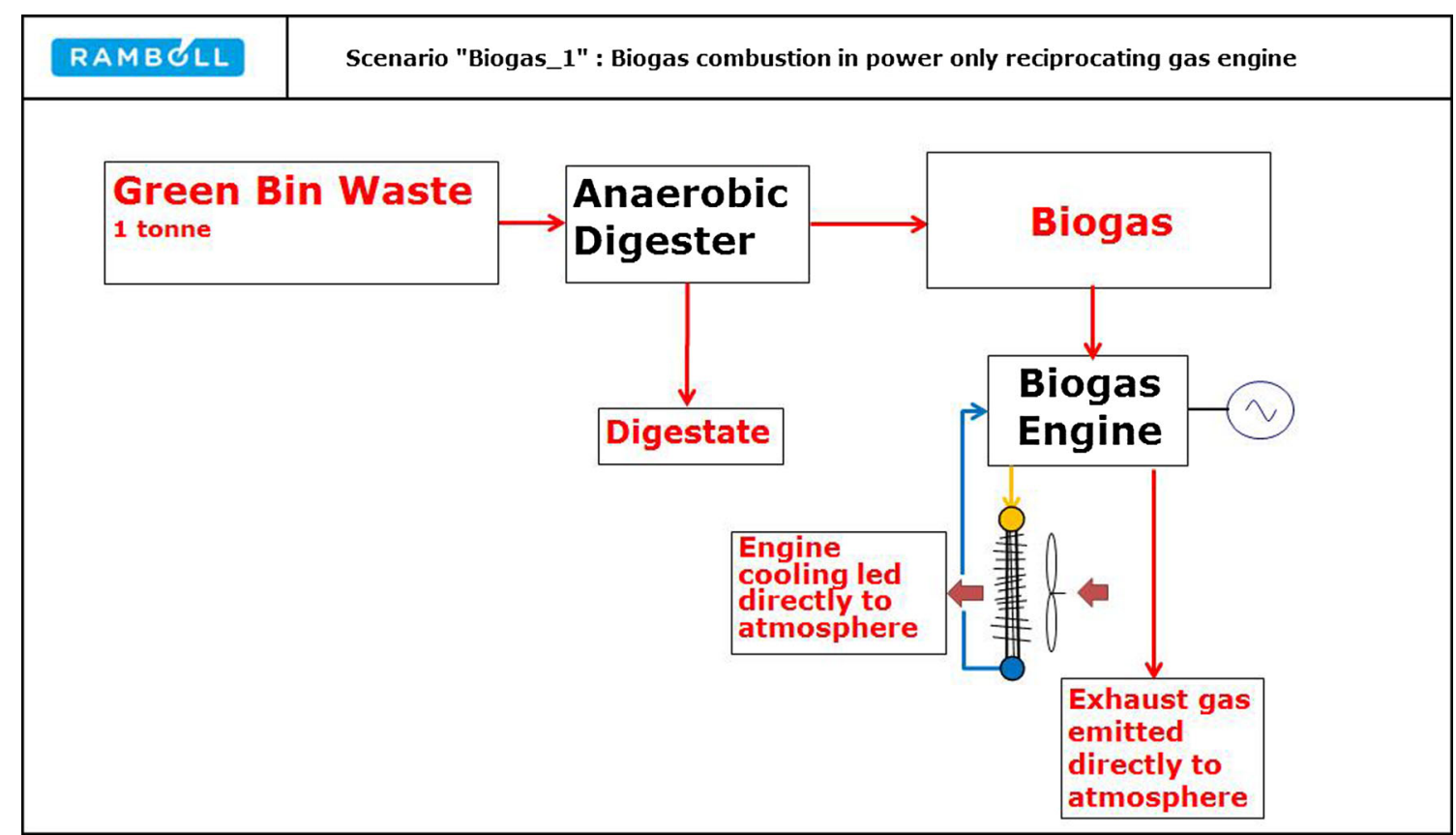

Fig. 6 Scenario "Biogas_1" where the formed biogas is used in a power-only gas engine

biogas, a mixture of methane and carbon dioxide. The process can occur at various conditions and production can be inhibited or accelerated by a number of factors. Detailed description of anaerobic digestion technology can be found in engineering textbooks such as [9].

Modeling of anaerobic digestion is extremely complex and beyond the scope of this paper. Few reports exist where sufficient coherent input and output information is available for full-scale digestion facilities. Therefore, the analysis is based on pilot-scale experiments as presented in [6•]. The key figures are presented in Table 5. Sample number corresponds to the characterization presented in Table 1.

Based on the figures presented in Tables 1 and 5, the biogas production and corresponding energy yield per ton of
Fig. 7 Scenario "Biogas_2" where the formed biogas is used in a combined heat and powerreciprocating gas engine

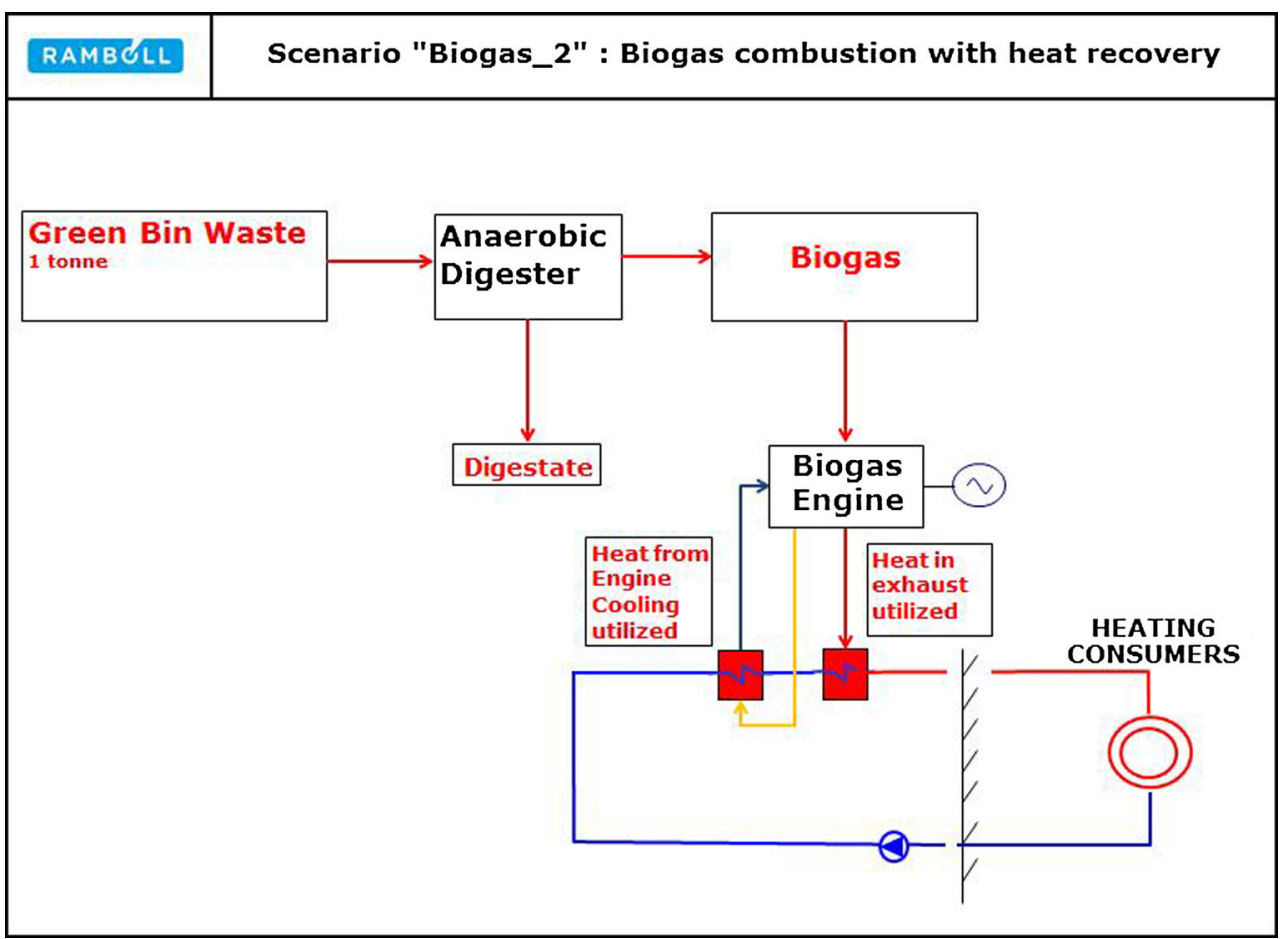




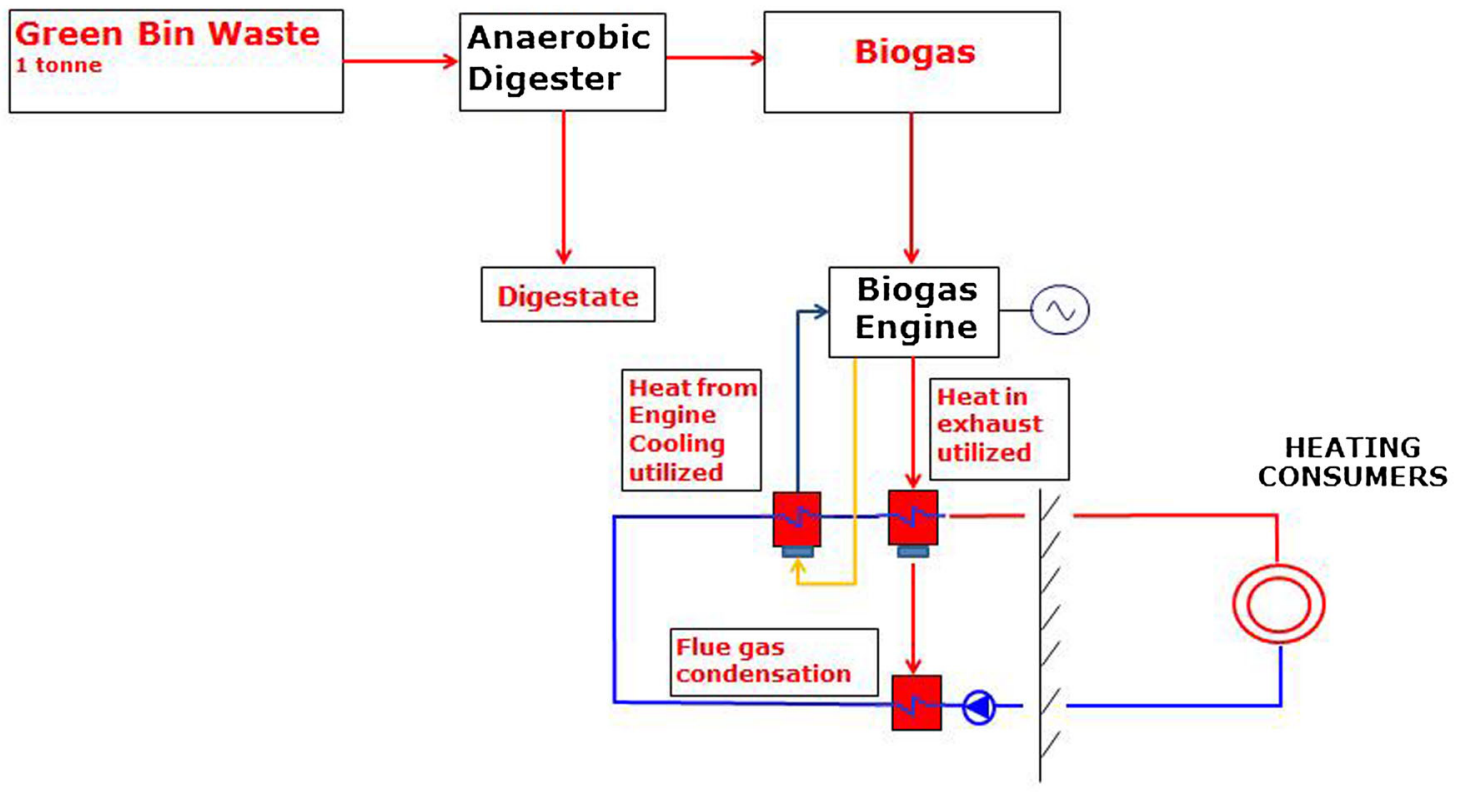

Fig. 8 Scenario "Biogas_3" where the formed biogas is used in a combined heat and power-reciprocating gas engine and where flue gas condensation is installed

incoming GBW is calculated. The biogas production per ton of GBW is calculated as

$\frac{\text { Measured } \mathrm{CH}_{4} \text { yield }\left[\mathrm{Nm}^{3} \mathrm{CH}_{4} / \text { ton VS }\right]}{\text { Average } \mathrm{CH}_{4} \text { content }[\mathrm{vol} \%]} \cdot \mathrm{VS}[\% \mathrm{TS}] \cdot \mathrm{TS}[\% \mathrm{w} / \mathrm{w}]$

The results are presented in Table 6. The average is used in the thermodynamic modeling. The lower heating value of methane is $35.883 \mathrm{MJ} / \mathrm{Nm}^{3}$.

\section{Energy Recovery in Reciprocating Gas Engine}

The biogas produced in the anaerobic digester is commonly used in a reciprocating gas engine. A simple sketch of the scenario where GBW is treated in an anaerobic digester and the formed biogas is combusted in a power-only, reciprocating gas engine is depicted in Fig. 6. The gross electrical efficiency of biogas engines is in practice roughly $40 \%$ mechanical [13]. The biogas engine is thermodynamically modeled in the comparison.

Table 7 Main assumptions for thermodynamic modeling. $G B W$ green bin waste, $C H P$ combined heat and power

\begin{tabular}{|c|c|c|}
\hline $\begin{array}{l}\text { Scenario } \\
\text { For Green Bin Waste }\end{array}$ & $\begin{array}{l}\text { Traditional Grate-fired Incineration Technology } \\
\text { Main Assumptions }\end{array}$ & $\begin{array}{l}\text { Biogas Plant } \\
\text { Main Assumptions }\end{array}$ \\
\hline Site 1: Power only & $\begin{array}{l}\text { Scenario "comb_1" } \\
\text { Live steam parameters } 440{ }^{\circ} \mathrm{C} / 70 \text { bara } \\
\text { turbine back pressure }=100 \mathrm{mbara} \\
\text { Boiler outlet } \mathrm{O}_{2}=8 \% \text { dry } \\
\text { Boiler outlet flue gas temperature }=160{ }^{\circ} \mathrm{C}\end{array}$ & $\begin{array}{l}\text { Scenario "biogas_1" } \\
134.6 \mathrm{Nm}^{3} \text { biogas/ton } \mathrm{GBW} \\
\text { Biogas composition: } 61.7 \% \mathrm{CH}_{4} \text { and } 38.3 \% \mathrm{CO}_{2} \\
\text { Engine efficiency }=40 \% \text { (gross) } \\
\text { Engine operated at } 8.7 \% \mathrm{O}_{2}\end{array}$ \\
\hline $\begin{array}{l}\text { Site 2: Combined heat } \\
\text { and power }\end{array}$ & $\begin{array}{l}\text { Scenario "comb_2" } \\
\text { As above, and additionally: } \\
\text { Heat used in district heating network }\end{array}$ & $\begin{array}{l}\text { Scenario "biogas_2" } \\
\text { As above, and additionally: } \\
\text { Engine-coupled CHP. Exhaust gas cooled to } 120{ }^{\circ} \mathrm{C}\end{array}$ \\
\hline $\begin{array}{l}\text { Site } 3 \text { : Combined heat } \\
\text { and power with flue } \\
\text { gas condensation }\end{array}$ & $\begin{array}{l}\text { Scenario "comb_3" } \\
\text { As above, and additionally: } \\
\text { Flue gas cooled additionally by a scrubber, } \\
\text { cooled by district heating return water } \\
\left(50^{\circ} \mathrm{C}\right) \text { Flue gas exits scrubber at } 52{ }^{\circ} \mathrm{C}\end{array}$ & $\begin{array}{l}\text { Scenario "biogas_3" } \\
\text { As above, and additionally: } \\
\text { Exhaust gas cooled additionally by a scrubber, } \\
\quad \text { cooled by district heating return water }\left(50^{\circ} \mathrm{C}\right) \\
\text { Exhaust gas exits scrubber at } 52^{\circ} \mathrm{C} \text {. }\end{array}$ \\
\hline
\end{tabular}


Table 8 Calculation algorithm for determining the marginal energy contribution and efficiency of a specific waste stream. HV_GBW denotes the heating value of green bin waste. The heating value can be either a lower or higher heating value, depending on preference. $M S W$ municipal solid waste

\begin{tabular}{lllll}
\hline & MSW Amount & GBW Amount & Electricity Production & Heat Production \\
\hline Mixed-incineration scenario & A & B & C & D \\
Baseline scenario & A & - & E & C-E \\
Energy contribution from GBW & - & - & (C-E)/B & D-F \\
Specific energy contribution & - & - & $((\mathrm{C}-\mathrm{E}) / \mathrm{B}) / \mathrm{HV}$ GBW & $(\mathrm{D}-\mathrm{F}) / \mathrm{B}$ \\
Marginal incinerator efficiency & - & - & & $(\mathrm{D}-\mathrm{F}) / \mathrm{B}) / \mathrm{HV} / \mathrm{GBW}$
\end{tabular}

\section{Reciprocating Gas Engine with Heat Recovery}

By running the gas engine in CHP mode, the heat of the exhaust gas and that from engine cooling is used in a district heating network. The total energy efficiency is thus increased (see Fig. 7).

\section{Reciprocating Gas Engine with Heat Recovery and Flue Gas Condensation}

Flue gas condensation installed after a biogas engine is not commonly seen. However, to create a level playing field in the comparison with the "Comb_3" scenario, a biogas scenario with CHP and flue gas condensation is generated (see Fig. 8).

The exhaust gas of the gas engine is cooled by the district heating return water, down to a temperature of $52{ }^{\circ} \mathrm{C}$. The overall efficiency of this scenario is thereby the highest of all biogas scenarios.

\section{Thermodynamic Modeling Assumptions}

The main assumptions used for the thermodynamic modeling in the previously presented scenarios are given in Table 7. For the four scenarios where heat is used in a district heating network, the network is assumed to have a supply temperature of $85{ }^{\circ} \mathrm{C}$ and a return temperature of $50{ }^{\circ} \mathrm{C}$.
The bio gas plant is assumed to produce at the average methane yield of the pilot scale experiments, cf. Table 5 .

\section{Methodology for Determining Marginal Incinerator Efficiency}

In Mass Burn Incineration, waste incineration technology combusts a mixture of different waste types. Because of the nature of incineration technology, the chemical composition and moisture content of the fuel influences how much energy can be recovered. This is especially owing to the fact that the flue gas is not cooled to temperatures below the boiling point of water. Thus, the latent heat in the flue gas vapor cannot be recovered in the boiler.

When comparing treatment technologies for a specific waste type, it can be very misleading to use average incinerator efficiencies. This should be done by means of determining the marginal efficiency of the fuel in question. To determine the marginal efficiency, it is necessary to construct a thermodynamic model of an incineration process. The marginal energy contribution and therefore efficiency is then determined by comparing a baseline scenario with a scenario where a fixed amount of the fuel in question is incinerated together with that in the baseline scenario. Table 8 describes the calculation algorithm.

The algorithm for calculating the marginal incinerator efficiency presented in Table 8 is applied to all three incineration scenarios and presented in Results. It is important to realize that the approach does not assume any synergy between the GBW and the other waste constituents.
Table 9 Scenario "Comb_1" results and determination of marginal efficiency based on lower heating value. $M S W$ municipal solid waste, $G B W$ green bin waste

\begin{tabular}{llll}
\hline & MSW amount & GBW amount & Electricity production \\
\hline Mixed-incineration scenario & $\mathrm{A}=30[\mathrm{t}]$ & $\mathrm{B}=1[\mathrm{t}]$ & $\mathrm{C}=96.47[\mathrm{GJ}]$ \\
Baseline scenario & $\mathrm{A}=30[\mathrm{t}]$ & - & $\mathrm{E}=95.32[\mathrm{GJ}]$ \\
Energy contribution from GBW & - & - & $96.47[\mathrm{GJ}]-95.32[\mathrm{GJ}]=1.15[\mathrm{GJ}]$ \\
Specific energy contribution & - & - & $1.15[\mathrm{GJ}] / 1[\mathrm{t}]=1.15[\mathrm{GJ} / \mathrm{t}]$ \\
Marginal incinerator efficiency & - & - & $1.15[\mathrm{GJ} / \mathrm{t}] / 4.3[\mathrm{GJ} / \mathrm{t}]=26.7 \%$ \\
\hline
\end{tabular}




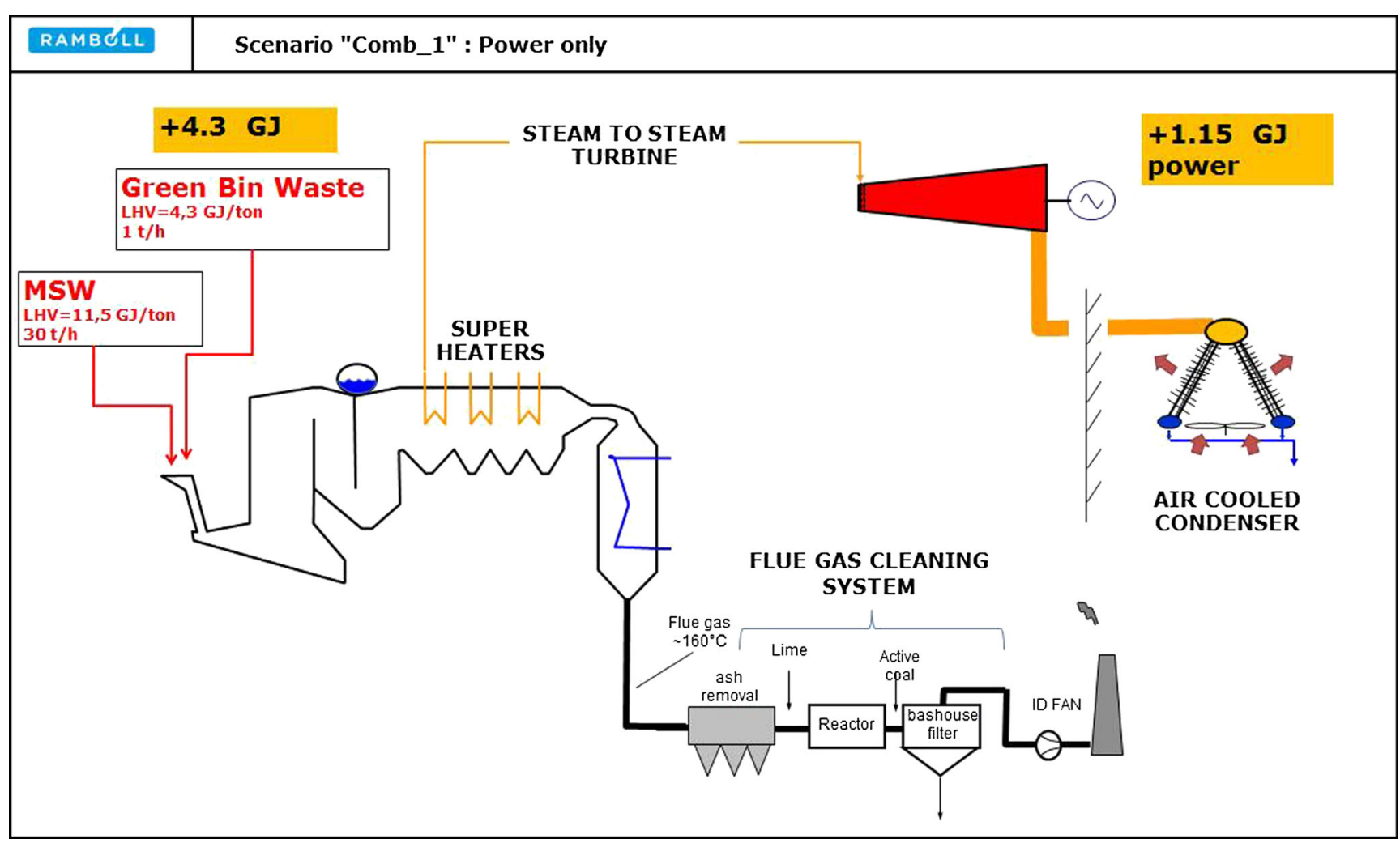

Fig. 9 Marginal energy contribution of adding 1 ton of GBW in the "Comb_1" scenario. $L H V$ lower heating value, MSW municipal solid waste

Results

The results of the modeling are presented below. All figures presented relate to the marginal energy contribution from the treatment of 1 ton of GBW with composition as presented in Table 1. The results are presented as a comparison of anaerobic digestion and mass burn incineration in pairs, so that the boundary conditions are equal.

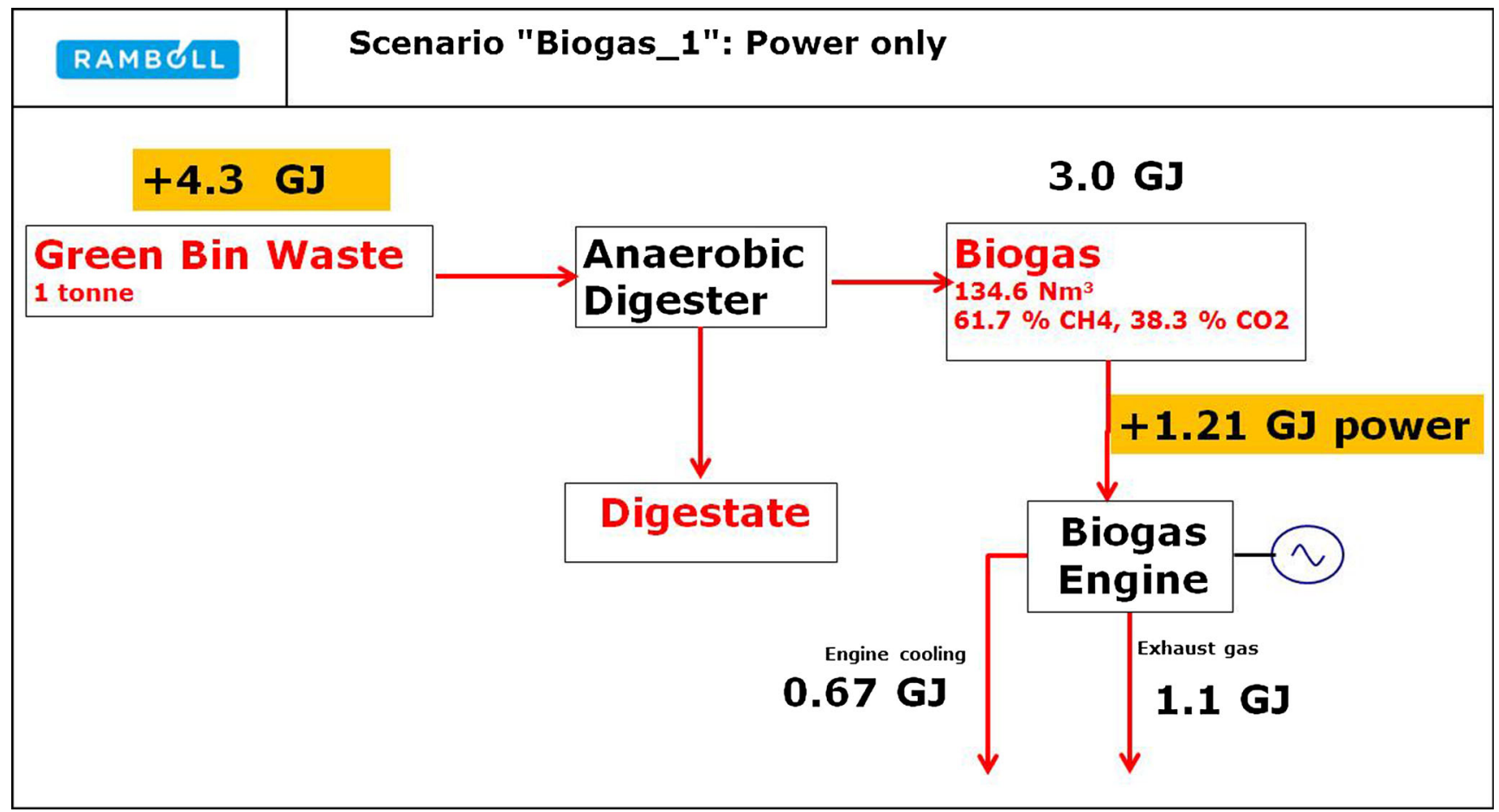

Fig. 10 Modeling results for the "biogas_1" scenario 


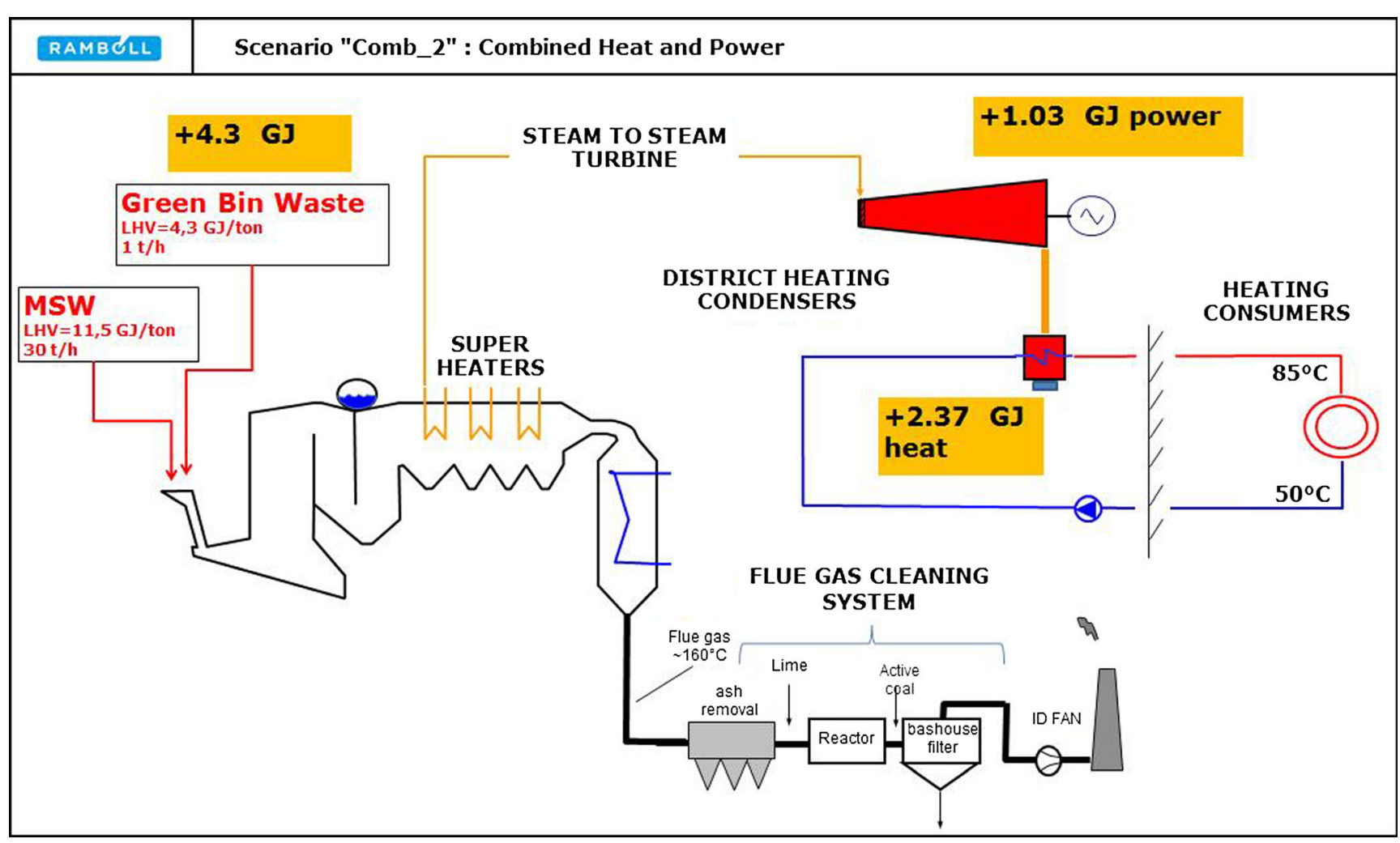

Fig. 11 Marginal energy contribution of adding 1 ton of green bin waste in the "Comb_2" scenario. $L H V$ lower heating value, $M S W$ municipal solid waste

Table 9 shows an example of the main modeling results of scenario "Comb_1" with the algorithm presented in Table 8 applied.

Figures 9, 10, 11, 12, 13 and 14 show the marginal energy contribution of 1 ton of GBW to the six scenarios. The marginal energy contribution of 1 ton of GBW is presented by the yellow boxes and based on the lower heating value.

\section{Discussion}

The modeling results and calculated efficiencies of all the scenarios are summarized in Table 10. The calculated efficiencies of using mixed MSW (as presented in Table 3) are also shown, to give a comparison to average considerations. Note that the electrical efficiency found in the biogas plant scenarios are gross. Parasitic consumption from stirring, pumping, heating, and control has not been included.

As seen in Table 10, the marginal efficiency for GBW reaches extreme levels if the incineration plant is equipped with flue gas condensation. As the efficiencies are based on the lower heating value, the condensation of flue gas vapor allows the overall efficiency to become greater than $100 \%$. Using the higher heating value as the base for the efficiency calculation, the marginal total efficiency in scenario "Comb 3" becomes $83.3 \%$.

The energy efficiency for the incineration of organic waste has in a previous study been assumed to have a total efficiency of $85 \%[1 \bullet]$. The modeling performed in this study found that for a plant with a total efficiency of $85.5 \%$ using mixed waste, dropped to a marginal total efficiency of only $79.1 \%$ when combusting GBW. Incinerator efficiency of $95 \%$ has been used as a representation of a plant equipped with flue gas condensation [2•]. The modeling in this study found this value to be within reach for mixed MSW. However, the marginal efficiency for GBW when incinerated in a plant with flue gas condensation was found to be $124 \%$. Thus, GBW has almost a one third higher degree of energy recovery than average efficiencies for plants equipped with flue gas condensation.

When equipping the biogas engine with flue gas condensation, the gain in energy recovery is limited. The reason for this is that the moisture content in the exhaust gas is low, thus having a low dew point.

Seventy percent of the energy in the GBW will be present in the formed biogas. The remaining $30 \%$ of the energy will be found as unconverted matter in the digestate and possibly gas leakages. Naturally, because the biogas yield is less than the theoretical potential, the overall efficiency of all the biogas scenarios is significantly lowered.

Based on the modeling results presented, it can be seen that comparisons of waste treatment options should be carried out keeping in mind whether or not heat is used and whether or not flue gas condensation is installed. Furthermore, incinerator efficiency should not only correspond to the technical set-up but also to the waste stream 


\section{RAMBCLL Scenario "Biogas_2": Combined Heat and Power}

$+4.3 \mathrm{GJ}$

Green Bin Waste

1 tonne

\section{$+1.34 \mathrm{GJ}$ total heat}

$3.0 \mathrm{GJ}$

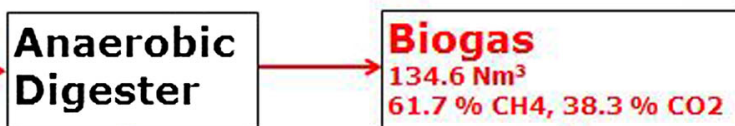

+1.21 GJ power

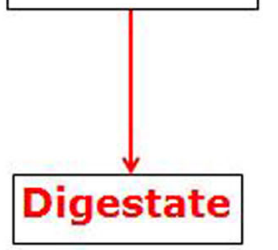

$61.7 \% \mathrm{CH} 4,38.3 \% \mathrm{CO} 2$

+1.21 Gower pow

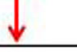

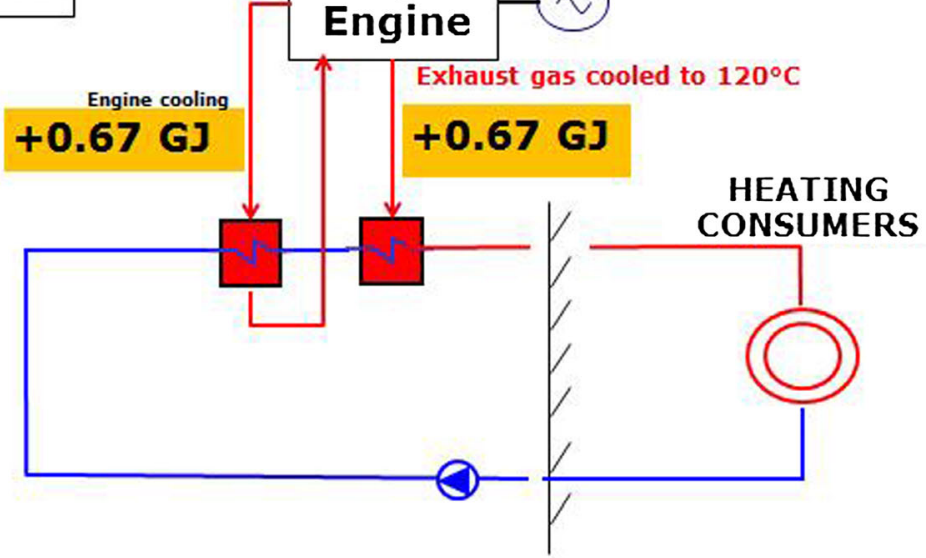

Fig. 12 Modeling results of the "biogas_2" scenario

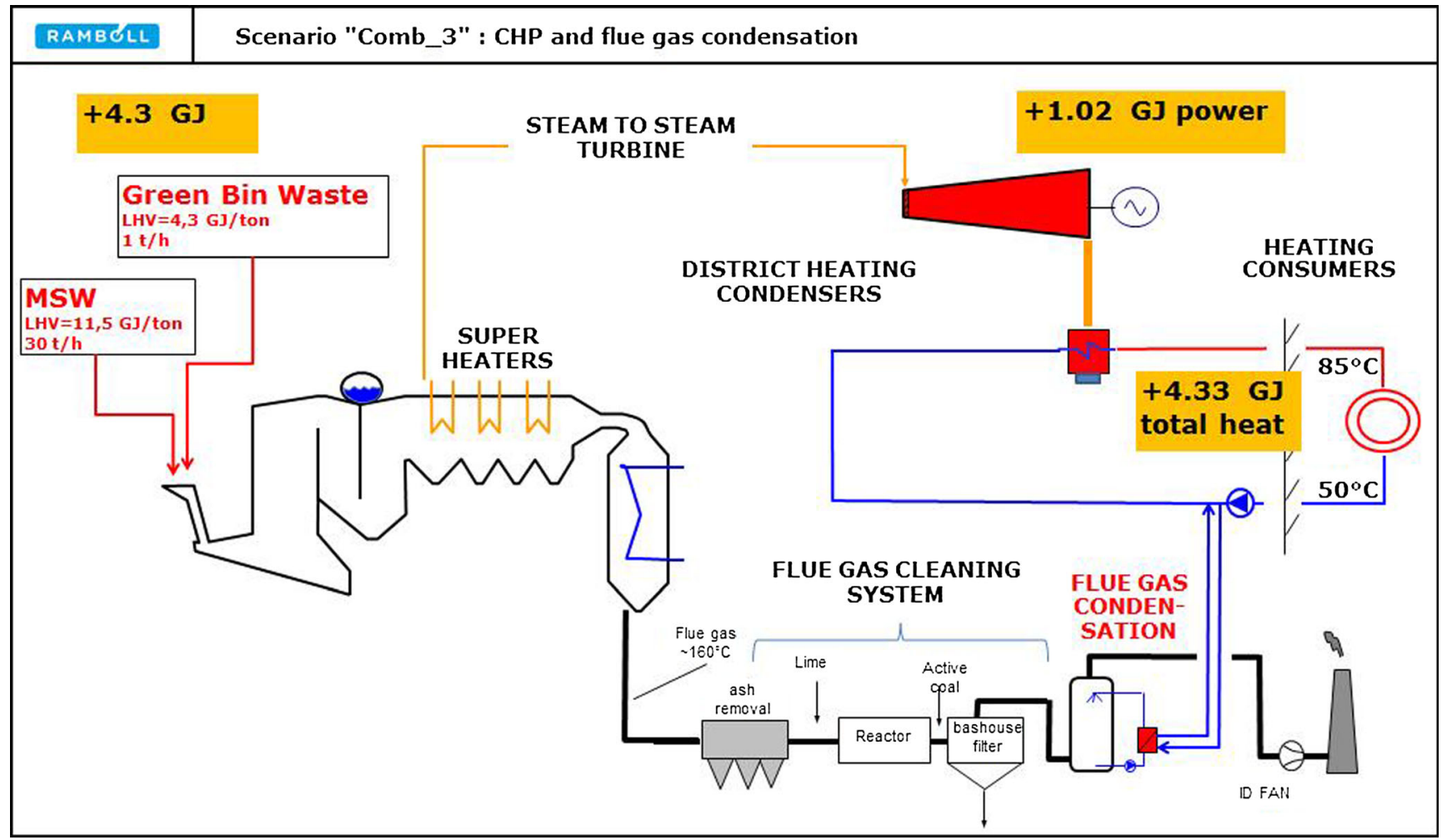

Fig. 13 Marginal energy contribution of adding 1 ton of green bin waster in the "Comb_3" scenario. $L H V$ lower heating value, $M S W$ municipal solid waste 


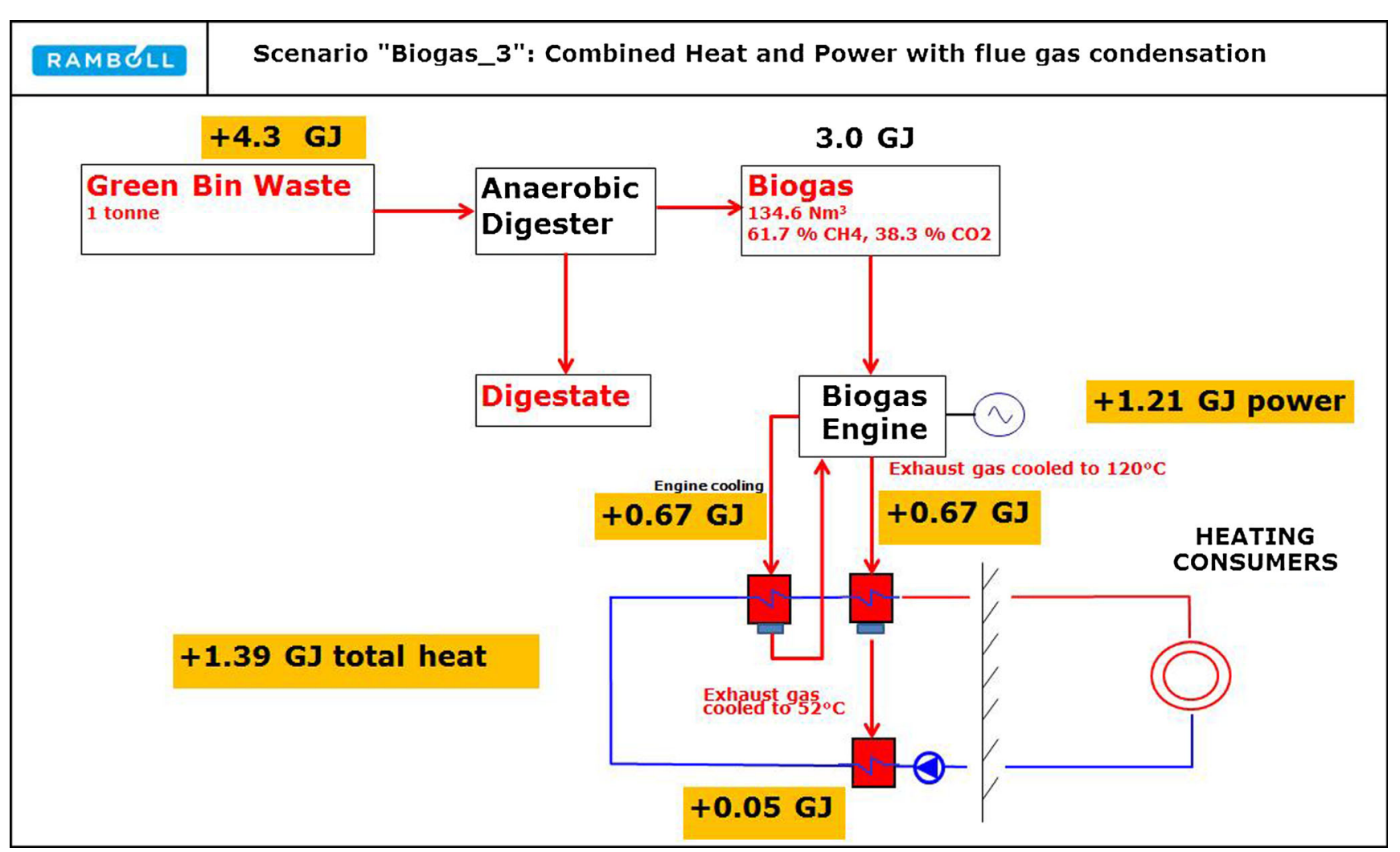

Fig. 14 Modeling results of the "biogas_3" scenario

being assessed. This especially applies to the incineration of organic waste. The very high efficiencies that can be achieved when incinerating organic waste will drastically affect any environmental evaluation. The authors would, however, like to underline that the evaluation only takes into account the mass and energy flows of the incineration process. Other residual effects of incineration of this highefficiency realization have not been quantified, albeit the change will be positive because of a better use of the waste. Furthermore, quantifying the overall impact of anaerobic digestion has not been the scope of this paper.

\section{Conclusion}

The study shows how to determine the marginal efficiency to be used analyzing incineration of a specific waste stream. The methodology was applied to the incineration of GBW and compared with the overall efficiency of an anaerobic digestion treatment system with direct biogas combustion in a reciprocating gas engine. The performance comparison was strictly with regard to energy conversion.

Although this study produces specific figures of energy recovery yields for a number of different scenarios for

Table 10 Calculated efficiencies for mixed MSW, marginal incinerator efficiency for GBW, and the efficiency of the biogas scenarios. Efficiencies are based on the lower heating value, which is the reason why efficiencies can exceed $100 \%$.

\begin{tabular}{lllll}
\hline Boundary Condition & Incineration & & \multirow{2}{*}{ Biogas Plant } \\
\cline { 2 - 3 } & Average Efficiency of Mixed MSW & Marginal Efficiency of GBW & Efficiency of GBW \\
\hline Power only & $27.9 \%$ net electrical efficiency & $26.7 \%$ net electrical efficiency & $28.1 \%$ gross electrical efficiency \\
Combined heat and power & $25.0 \%$ net electrical efficiency & $24.0 \%$ net electrical efficiency & $28.1 \%$ gross electrical efficiency \\
& $60.5 \%$ district heat & $55.1 \%$ district heat & $31.2 \%$ district heat \\
Combined heat and power & Total efficiency: $85.5 \%$ & Total efficiency: $79.1 \%$ & Total efficiency: $59.3 \%$ \\
with flue gas condensation & $24.9 \%$ net electrical efficiency & $23.3 \%$ net electrical efficiency & $28.1 \%$ gross electrical efficiency \\
& $68.9 \%$ district heat, of which & $100.7 \%$ district heat, of which & $32.3 \%$ district heat, of which \\
& $8.4 \%$ flue gas condensation & $44.9 \%$ flue gas condensation & $1.2 \%$ flue gas condensation \\
& Total efficiency: $93.8 \%$ & Total efficiency: $124.0 \%$ & Total efficiency: $60.5 \%$ \\
\hline
\end{tabular}

Note that the efficiency of the biogas scenario is given as gross as opposed to net. This is because values for own energy consumption of the biogas plant have not been found in literature. The net efficiency will be lower than gross. $G B W$ green bin waste, $M S W$ municipal solid waste 
incineration and biogas production, the aim of the study is not a technology comparison as such. A proper technology comparison, including life-cycle assessments, should deal with many other issues than just energy recovery, for instance, other environmental factors, initial cost, operating and maintenance costs, and commercial aspects.

The main conclusion is that efficiencies used for comparisons of technology must be waste-type (and calorific-value) specific, to obtain reliable results in the assessment.

Thus, adopting the concept of marginal efficiencies for incineration is necessary to create a leveled playing field when comparing waste treatment options for specific waste streams. It does not provide a realistic result to use "average waste" efficiencies for incinerators, when analyzing specific waste fraction, such as GBW.

\section{Compliance with Ethics Guidelines}

Conflict of Interest Lasse Tobiasen, Kristian Kahle, Claus Hindsgaul, and Bettina Kamuk have no conflicts of interest.

\section{Bibliography}

Papers of particular interest, published recently, have been highlighted as:

- Of importance

1. Fruergaard T, Astrup, T. Optimal utilization of waste-to-energy in an LCA perspective. 2011, Waste management 31, pp. 572-582. Study indicates average conditions.
2. Miljøstyrelsen. Miljø- og samfundsøkonomisk vurdering af muligheder for øget genanvendelse af papir, pap, plast, metal og organisk affald. Miljøprojekt nr. 1458. Copenhagen: Miljøstyrelsen (Danish Environmental Protection Agency), 2013. Study indicates average conditions.

3. Finnveden $\mathrm{G}$ et al. Life cycle assessment of energy from solid waste - part 1: general methodology and results. J Clean Prod. 2005;13(3): 213-29.

4. Eriksson $\mathrm{O}$ et al. Municipal solid waste management from a systems perspective. J Clean Prod. 2005;13(3):241-52.

5. Edelmann W, Baier U, Engeli H. Environmental aspects of the anaerobic digestion of the organic fraction of municipal solid wastes and of solid agricultural wastes. Water Sci Technol. 2005;52(1):203-8.

6. Åsa, et al. Methane yield in source-sorted organic fraction of municipal solid waste. Davidsson, 2007, Waste Management 27, pp. 406-414. These results are used as the basis for the definition of green bin waste and methane yield.

7. Schwanecke, R. Formeln und Hilfsnomogramme für die Anwendung der Technischen Anleitung zur Reinhaltung der luft. Wasser, Luft und Betrieb, Vol. 20, pp. 607-609.

8. Martin JJE, Koralewska R. s.l. Martin waste-to-energy technology.: Springer, 2013, Renewable Energy Systems, Vol. 2, pp. 1201-1248.

9. Christensen TH. Solid waste technology \& management. Vol. 2. Chichester: Wiley; 2011.

10. Tobiasen L, Kamuk B. Waste-to-energy for district heating. [book auth.] Nickolas J. Themelis and Martin Kaltschmitt. Renewable Energy Systems. s.1.: Springer Reference, 2012, pp. 1542-1560.

11. Götaverken Miljö AB. Brochures. [Online] http://www.gmab.se/ eng_trycksaker.htm.

12. Hitachi Zosen Inova. [Online] http://www.hz-inova.com/cms/en/ technology-solutions/flue-gas-treatment/wet-scrubbing/ condensing-scrubber.

13. Clarke Energy. Biogas engines. [Online] 7 February 2013. http://www.clarke-energy.com/2013/chp-cogen-efficiencybiogas/. 